\title{
UMA ANÁlISE DO CAPÍTULO “O CONCEITO DE ESCLARECIMENTO” DA DIALÉTICA DO ESCLARECIMENTO DE ADORNO E HORKHEIMER
}

\author{
AN ANALYSIS OF THE CHAPTER "THE CONCEPT OF ENLIGHTENMENT" OF THE DIALECTIC OF \\ ENLIGHTENMENT OF ADORNO AND HORKHEIMER
}

Ítalo Menezes Campos*

\section{RESUMO}

A Dialética do esclarecimento possui dificuldades muito peculiares. Ela foi escrita em um contexto conturbado quando Adorno e Horkheimer se refugiavam da Alemanha nazista nos Estados Unidos. Seu texto desafia nosso entendimento a percorrer caminhos que são no mínimo incomuns. O caráter fragmentário da obra é reconhecido pelos próprios autores. Porém, dentre todas as suas complexidades, uma se destaca por ser a base de toda a obra: o caráter regressivo do esclarecimento. Seu primeiro capítulo, cujos principais pontos iremos expor, propõe uma análise histórica do esclarecimento que vai muito além do "século das luzes". Trata-se de mostrar que o domínio da natureza pelo homem se volta para ele como domínio da sua própria natureza interna e de resgatar concepções do pensamento mítico e religioso que permitem vislumbrar o desenvolvimento obscuro do esclarecimento. Trata-se de falar da própria razão. Um desafio e uma aporia diante dos quais os autores não recuam. Compreender esse procedimento é o primeiro passo para adentrar nessa obra.

PALAVRAS-CHAVE: teoria crítica; esclarecimento; indústria cultural; antissemitismo; regressão.

\begin{abstract}
The Dialectic of enlightenment has very peculiar difficulties. It was written in a troubled context when Adorno and Horkheimer took refuge from Nazi Germany in the United States. His text challenges our understanding to follow paths that are at least unusual. The fragmentary character of the work is recognized by the authors themselves. However, among all its complexities, one stands out for being the basis of the whole work: the regressive character of enlightenment. Its first chapter, whose main points we will expose, proposes a historical analysis of the enlightenment that goes far beyond the "century of lights". It is about showing that the domain of nature by man turns to him as a domain of his own internal nature and rescuing concepts of mythical and religious thought that allow us to glimpse the dark development of enlightenment. It is about talking about reason itself. A challenge and an aporia before which the authors do not back down. Understanding this procedure is the first step to enter this work.
\end{abstract}

KEYWORDS: Critical theory; clarification; cultural industry; anti-semitism; regression.

\footnotetext{
* Graduado em Filosofia pela PUC Minas. E-mail: itlcampos@ hotmail.com.
} 


\section{INTRODUÇÃO}

Theodor W. Adorno (1903-1969) e Max Horkheimer (1895-1973) escreveram juntos a Dialética do esclarecimento (2006) na década de 1940. O livro teve uma primeira versão em 1944, chamada "Fragmentos filosóficos", e sua versão comercial em 1947. A obra é muitas vezes considerada uma mera aporia. Um livro pessimista que não vislumbra possibilidades reais de emancipação. Mas trata-se de uma aporia reconhecida pelos seus próprios autores. No prefácio da obra, Adorno e Horkheimer (2006, p. 13) afirmam: "a aporia com que defrontamos em nosso trabalho revela-se assim como o primeiro objeto a investigar: a autodestruição do esclarecimento". Essa investigação é base de toda a obra, seja quando tratam da indústria cultural ou do antissemitismo. Embora isso possa parecer óbvio, visto que se trata do primeiro capítulo e que seu tema já é apresentado no título do livro, é muito fácil nos perdermos na escrita turva de seus autores e no caráter fragmentário de suas teses. Nossa comunicação pretende apenas analisar a crítica feita ao esclarecimento no primeiro capítulo da obra, "O conceito de Esclarecimento", para que se possa ter uma base mínima, mas que seja condicionante para a leitura do restante da obra.

\section{O ESCLARECIMENTO}

O Iluminismo se caracterizou por uma aposta na razão como aquela capaz de melhorar a vida humana por meio do progresso e da libertação do engano. Seu objetivo prático era tornar as pessoas mais felizes. A transmissão do conhecimento, bem representada pela Enciclopédia, era baseada na "convicção de que o estímulo à instrução determina também o crescimento da virtude e da felicidade" (BOBBIO; MATTUCCI; PASQUINO, 1998, v. 1, p. 608). Kant, o representante do Iluminismo alemão, sustentou que os indivíduos deveriam conhecer por si mesmos: "Sapere aude! ${ }^{1}$ tem coragem de fazer uso de teu próprio entendimento, tal é o lema do esclarecimento [Aufklärung] ${ }^{20}$ (KANT, 1985, p. 100). Na Dialética do esclarecimento

\footnotetext{
${ }^{1}$ Ousa saber!

${ }^{2}$ A tradução do termo Aufklärung por "esclarecimento" nesta passagem merece uma explicação, pois é a mesma opção feita pelo tradutor da edição da Dialética do esclarecimento (2006) que utilizamos. "Iluminismo" ou "ilustração" são termos que, para nós, normalmente remetem ao momento histórico a que nos referimos acima. "Esclarecimento", por sua vez, é um correspondente exato do sentido que há no uso corrente do termo Aufklärung na língua alemã, "por exemplo em contextos como: sexuelle Aufklärung (esclarecimento sexual) ou politische Aufklärung (esclarecimento político)." [Trata-se, portanto, do] "processo pelo qual uma pessoa vence as trevas da ignorância e do preconceito em questões de ordem prática (religiosas, políticas, sexuais etc.)" (ALMEIDA, 2006, p. 7).
} 
(2006), Adorno e Horkheimer se perguntam como uma sociedade desenvolvida sobre as bases do esclarecimento ainda é capaz de promover a barbárie. Por que de fato o progresso técnico não foi capaz de eliminar as desigualdades sociais e realizar a felicidade humana? A tese principal dos nossos autores no capítulo "O conceito de esclarecimento" é que não apenas o esclarecimento regride a uma nova forma de mitologia, mas que o próprio mito já era uma forma de esclarecimento. Horkheimer (2015, p. 39) já havia apontado para isso na obra Eclipse da razão:

Toda ideia filosófica, ética e política - cortados os laços que a relacionavam com suas origens históricas - tem uma tendência a tornar-se o núcleo de uma nova mitologia, e essa é uma das razões pelas quais o avanço do esclarecimento tende, em certos pontos, a inverter-se em superstição e paranoia.

Por isso seu trabalho com Adorno consiste também em retomar as origens históricas do esclarecimento a fim de mostrar que pretensões expressas apenas na modernidade já se encontravam em concepções religiosas e míticas muito antigas. Vamos primeiro analisar alguns pontos da crítica dos autores à dominação técnica da natureza para depois mostrar a gênese dos problemas apontados já no pensamento antigo.

\subsection{O domínio da natureza}

Nossos autores concentram sua crítica em grande parte na figura de Francis Bacon (1561-1626), que é tomado como uma espécie de "arauto da racionalidade científica moderna" (DUARTE, 2009). De fato, Bacon foi um defensor confesso de uma ciência operativa que busca manipular e dominar a natureza, mas com o intuito de melhorar a vida humana. De nada adiantaria um conhecimento teórico que não fosse capaz de prover melhores condições para nossa vida. Na conhecida obra de 1620, Novum Organum, ele advoga explicitamente a "vitória sobre a natureza, pela ação" (BACON, 1973, p. 14). O verdadeiro conhecimento seria obtido pela via de uma cautelosa indução que teria por origem os dados da experiência e que não se apressasse para chegar a suas leis mais gerais. A partir dessa indução seria possível interpretar corretamente a natureza, não para imitá-1a ${ }^{3}$, mas para dominá-la, “pois a natureza não se vence,

\footnotetext{
${ }^{3}$ Desde os gregos, as mais diversas formas de arte são vistas como alguma forma de imitação da natureza, seja para contemplá-la, buscando um prazer estético, ou para melhor se aproveitar dela, desenvolvendo artefatos úteis para a satisfação de necessidades humanas. Bernardo Jefferson de Oliveira (2010, p. 128-132) relata a mudança que Bacon promove nessa concepção ao defender que a arte humana seria capaz mesmo de alterar a natureza em
} 
se não [sic] quando se lhe obedece" (BACON, 1973, p. 19). Porém, obedecê-la não significa se submeter às suas manifestações externas, mas compreender seus princípios mais internos, de modo que se possa reproduzi-la para dela se servir:

A natureza se torna verdadeiramente disponibilizada (liberta) somente quando decifrada e reproduzida pelo homem. Torna-se livre no sentido de aberta à interpretação de novas manifestações e novas possibilidades de operação. A nova ciência, enquanto conhecimento verdadeiramente operante, liberta a natureza ao liberar, através da manipulação, seus poderes escondidos. (OLIVEIRA, 2010, p. 137).

Logo, para Bacon, a dominação da natureza passa por uma identificação daquilo que é produto da ação humana com a própria natureza. A citação abaixo explicita esse ponto:

[...] afirmou-se a inveterada opinião de que arte é coisa diferente da natureza e as coisas artificiais [diferentes] das naturais. Daqui derivou o inconveniente de que muitos escritores de coisas naturais creem ter alcançado seu objetivo compondo uma história dos animais, dos vegetais, dos minerais e omitindo os experimentos das artes mecânicas. Mas um preconceito ainda mais sutil insinuou-se na mente dos homens: a arte não passa de uma espécie de apêndice da natureza, que teria apenas a tarefa de completar aquilo que a natureza somente iniciou, de assisti-la quando ela se deteriora ou de libertá-la quando está impedida, mas nunca a tarefa de resolvê-la profundamente, de transmutá-la, de abalá-la até suas profundezas. Isso provocou um precipitado desespero nas coisas humanas. Pelo contrário, esse outro princípio deveria ter penetrado em profundidade nas mentes: as coisas artificiais não diferem das naturais pela forma ou pela essência, mas apenas pela causa eficiente (...) quando as coisas estão dispostas à obtenção de um determinado efeito, pouco importa que este seja alcançado pelo homem ou sem o homem. (BACON apud OLIVEIRA, 2010, p. 139).

Nesse contexto, faz todo sentido Bacon (1973, p. 93) mencionar que "o homem é Deus para o homem”. O indivíduo da ciência que ele propõe é soberano, conhece, domina e faz a natureza. Saber e poder coincidem. Mas há um preço a se pagar por isso. Segundo nossos autores, esse saber não conhece limites, ele está a serviço dos fins da economia burguesa tanto nas fábricas quanto nos campos de batalha (ADORNO; HORKHEIMER, 2006, p. 18). A dominação não se contenta com as coisas, ela alcança os homens também. Tomar a natureza como uma mera matéria sem qualidades a ser classificada tem por consequência a dissolução das qualidades no próprio pensamento. A dominação da natureza não apenas pressupõe uma separação radical entre ela e seu dominador, mas implica ainda "[...] o reconhecimento do poder como o princípio de todas as relações" (ADORNO; HORKHEIMER, 2006, p. 21). A

suas fundações, descobrindo coisas que ela jamais revelaria. Lembramos também que "arte" aqui deve ser entendida em sua concepção antiga (téchne), que, em geral, se referia a uma habilidade produtiva, mas também a um conhecimento teórico que justificasse determinado procedimento (OLIVEIRA, 2010, p. 23-24). 
dominação é o modo de conhecimento do homem da ciência. É justamente esse princípio e a submissão que lhe é correlata que se procura identificar no pensamento mítico e religioso dos antigos.

\subsection{Mito e esclarecimento}

Diferentemente do que ocorre na ciência moderna, o xamã não se dirigia a um mero exemplar. Embora seu objetivo pudesse ser, por exemplo, a cura de um doente, sua magia lidava com uma multiplicidade que transcendia a experiência sensível. "Os ritos do xamã dirigiam-se ao vento, à chuva, à serpente lá fora ou ao demônio dentro do doente, não a matérias ou exemplares. [...] O feiticeiro torna-se semelhante aos demônios; para assustá-los ou suavizálos, ele assume um ar assustadiço ou suave." (ADORNO; HORKHEIMER, 2006, p. 21). No ritual, a natureza é mobilizada não como objeto, mas por uma relação de parentesco. $\mathrm{O}$ homem primitivo ainda não forjou a sua identidade em oposição à realidade (como ocorrerá na ciência), seu método é a mimese ${ }^{4}$. Mesmo um dos princípios religiosos mais antigos, o "mana", que representa "aquilo que transcende o âmbito da experiência, aquilo que nas coisas é mais do que sua realidade já conhecida, [...] não é uma substância espiritual oposta à substância material, mas o emaranhado da natureza em face do elemento individual" (ADORNO; HORKHEIMER, 2006, p. 25).

Adorno e Horkheimer identificam nesses modos de relação com a natureza, ainda que de forma embrionária, concepções que se destacariam no esclarecimento moderno. Se uma árvore, por exemplo, podia ser considerada sede do mana, ela encerrava em si uma contradição que já prefigurava a pretensão de objetividade do conceito que se separa da coisa a que se refere, antecipando o modo de conhecimento da ciência positiva (ADORNO; HORKHEIMER, 2006, p. 26). Do mesmo modo, quando ocorre alguma divisão social nas tribos, os que são mais velhos e dominam os feitiços passam a ser uma espécie de representantes do sagrado, podendo materializá-lo já com alguma autonomia. Também a divisão de tarefas entre os membros da tribo se torna reflexo de uma ordem transcendente que se estende na imanência, cada um tem o seu lugar correto determinado por algo superior. "[...] o curso da natureza enquanto eflúvio do mana já está erigido em norma, que exige a submissão.” (ADORNO; HORKHEIMER, 2006,

\footnotetext{
${ }^{4}$ Não estamos afirmando aqui que a mimese se restringe ao homem primitivo, sabemos que esse conceito é importante ainda hoje para a filosofia da arte. Queremos destacar que o modo de relação do homem moderno com a natureza é a dominação, e não a imitação, como no homem primitivo.
} 
p. 30). Se outrora era a natureza que estabelecia a ordem terrena, quem assumirá seu papel será a ordem econômica capitalista, na qual a submissão ganha uma nova forma com a divisão de classes sociais.

Outro ponto fundamental é a linguagem. Signo e imagem originariamente estavam juntos, como nos hieróglifos, mas a função imagética posteriormente passaria para os mitos. Tanto o ritual mágico quanto os mitos têm por conteúdo a repetição da natureza, seus símbolos demonstram isso, seja pela imagem do Ovo, da Mãe primordial ou da Vaca, que representam uma renovação infinita (ADORNO; HORKHEIMER, 2006, p. 27). Mas quando o mito é sistematizado, essa repetição toma o caráter do inevitável. Nossos autores dão o exemplo do mito que associa o rapto da Perséfone às mudanças das estações do ano. Se antes o rapto era identificado com a morte da natureza, ele se repetia sempre a cada outono, embora fosse o mesmo, era sempre novo. Mas com a fixação da sua ocorrência no passado, o rapto ocorre uma única vez, e aquilo que é novo, o ciclo das estações, se torna predeterminado, portanto, apenas ocorrência do velho (ADORNO; HORKHEIMER, 2006, p. 34-35). Em suma:

\begin{abstract}
O mito queria relatar, denominar, dizer a origem, mas também expor, fixar, explicar. Com o registro e a coleção dos mitos, essa tendência reforçou-se. Muito cedo deixaram de ser um relato, para se tornarem uma doutrina. Todo ritual inclui uma representação dos acontecimentos bem como do processo a ser influenciado pela magia. Esse elemento teórico do ritual tornou-se autônomo nas primeiras epopeias dos povos. Os mitos, como os encontraram os poetas trágicos, já se encontram sob o signo daquela disciplina e poder que Bacon enaltece como o objetivo a se alcançar. (ADORNO; HORKHEIMER, 2006, p. 20).
\end{abstract}

Porém, uma vez que a ciência denuncia o mito como mera fantasia, a linguagem se resigna à função apenas de signo. Mesmo que os mitos tenham em algum momento se transformado em doutrina, os deuses ainda eram símbolo da natureza enquanto poder universal. Quando o mundo se desencanta ${ }^{5}$, resta à linguagem a limitação àquilo que é imediatamente dado. Não são os deuses somente que são abolidos, mas também a própria pretensão do conhecimento:

Compreender o dado enquanto tal, descobrir nos dados não apenas suas relações espaço-temporais abstratas, com as quais se possa então agarrá-las, mas ao contrário pensá-las como a superfície, como aspectos mediatizados do conceito, que só se

\footnotetext{
5 A noção de desencantamento do mundo, de Max Weber (1864-1920), também é utilizada por Adorno e Horkheimer (2006, p. 17) para sintetizar o programa do esclarecimento. O conceito weberiano basicamente trata da passagem de uma racionalidade religiosa para uma econômica, o "racional" toma o lugar do "mágico" (NOBRE, 2018).
} 
realizam no desdobramento de seu sentido social, histórico, humano - toda pretensão do conhecimento é abandonada. (ADORNO; HORKHEIMER, 2006, p. 34).

Ao abandonar essa pretensão, o sujeito se coisifica. Embora o eu tenha se tornado o princípio da razão, ele é cada vez mais dependente de uma ordem econômica da qual ele não consegue escapar. A autoconservação, que segundo nossos autores é fundamento de toda a civilização ocidental (ADORNO; HORKHEIMER, 2006, p. 36), se reduz à condição em que cada um deve ocupar o lugar que lhe é determinado em uma sociedade de classes. Assim a dominação da natureza se converte na submissão da qual a humanidade tanto tentou escapar, regredindo, portanto, em uma nova forma de mitologia. Esse entrelaçamento entre mito, dominação e trabalho é exemplificado com um dos episódios da epopeia de Homero.

No canto XII da Odisseia (HOMERO, 2015), um dos obstáculos enfrentados por Ulisses no seu retorno a Ítaca foi ter de resistir ao canto das sereias. Já alertado por Circe, sabendo que nem ele e nem seus companheiros seriam capazes de sucumbir à tentação, tampa com cera os ouvidos daqueles que remam e manda que eles o amarrem no mastro da embarcação para que, quando ouvisse o canto, não fosse ao encontro das sereias. Para se preservar, Ulisses precisa renunciar a si mesmo. Privilegiado, ele escuta o canto, mas quanto mais forte a sedução, mais forte ele é amarrado, "exatamente como, muito depois, os burgueses, que recusavam a si mesmos a felicidade com tanto maior obstinação quanto mais acessível ela se tornava com o aumento de seu poderio" (ADORNO; HORKHEIMER, 2006, p. 40). Seus companheiros, assim como os trabalhadores nas fábricas ou nos escritórios, são privados da beleza, sabem apenas do perigo que os força a remar com maior afinco. Os autores ainda comparam a posição de Ulisses com a do espectador de um concerto:

\footnotetext{
Ulisses assiste a um concerto, a escutar imóvel como os futuros frequentadores de concertos, e seu brado de libertação cheio de entusiasmo já ecoa como um aplauso. Assim a fruição artística e o trabalho manual já se separam na despedida do mundo pré-histórico. A epopeia já contém a teoria correta. O patrimônio cultural está em exata correlação com o trabalho comandado, e ambos se baseiam na inescapável compulsão à dominação social da natureza. (ADORNO; HORKHEIMER, 2006, p. 40).
}

Vê-se, portanto, que a denúncia feita pelos autores consiste em evidenciar que, paradoxalmente, a irracionalidade da nossa sociedade é fruto de uma aposta irrestrita na razão. Uma vez que a razão destituiu tudo que ficou para trás de si como fantasia e engano, não há mais nada que possa lhe impor limites, seu princípio, que na verdade é o da dominação, não priva a natureza e nem as pessoas. 


\section{CONCLUSÃO}

O capítulo que analisamos termina com a afirmação de que o esclarecimento se torna mistificação das massas. Ou seja, se converte exatamente no seu oposto. O indivíduo reivindicado na proposta iluminista, que consiste em um sujeito alçado à posição de senhor e dominador da natureza, se verá antagonicamente na condição de objeto da sua própria pretensão dominadora. $\mathrm{O}$ alcance desse engano será tratado nos capítulos seguintes, sobretudo quando se aborda a indústria cultural. Mas essa contradição alcança seu ápice na barbárie nazista. Não tivemos espaço aqui para abordar esses assuntos, mas foram críticas tão contundentes à cultura e à sociedade, que ainda permanecem suscitando debates. Sabemos que seria impróprio simplesmente transpor uma crítica feita na década de 1940, em um contexto específico, para os dias atuais. Na verdade seria um disparate fazer isso com um pensamento que tem na própria transformação da sociedade a condição do seu exercício. Mas o alerta para que a razão seja capaz de refletir sobre si mesma certamente permanece. Pensamos que recusar a crítica dos autores simplesmente por conta de sua aporia pode significar a cegueira para as contradições da própria sociedade. E o primeiro passo para lidar com essas contradições é não recuar diante delas, mas trazê-las à superfície. Precisamente esse é o passo dado por Adorno e Horkheimer.

\section{REFERÊNCIAS}

ADORNO, Theodor W.; HORKHEIMER, Max. Dialética do esclarecimento. Tradução de Guido de Antônio Almeida. Rio de Janeiro: Zahar, 2006.

ALMEIDA, Guido de Antônio. Nota preliminar do tradutor. In: ADORNO, Theodor W.; HORKHEIMER, Max. Dialética do esclarecimento. Tradução de Guido de Antonio Almeida. Rio de Janeiro: Zahar, 2006. p. 7-8.

BACON, Francis. Novum organum ou verdadeiras indicações acerca da interpretação da natureza. Tradução de José Aluysio Reis Andrade. São Paulo: Abril Cultural, 1973. (Os pensadores, XIII).

BOBBIO, Norberto; MATTEUCCI, Nicola; PASQUINO, Gianfranco. Dicionário de política. Tradução de Carmen C. Varriale et al. Brasília: Editora Universidade de Brasília, 1998. v. 1.

DUARTE, Rodrigo. Sobre o conceito dialético de esclarecimento. In: DUARTE, Rodrigo; TIBURI, Márcia (org.). Seis leituras sobre a Dialética do esclarecimento. Ijuí: Unijuí, 2009. p. 13-26. 
HOMERO. Odisseia. Tradução de Carlos Alberto Nunes. 25. ed. Rio de Janeiro: Nova Fronteira: 2015.

HORKHEIMER, Max. Eclipse da razão. Tradução de Carlos Henrique Pissardo. São Paulo: Unesp, 2015.

KANT, Immanuel. Resposta à pergunta: Que é "Esclarecimento" [“Aufklärung”]? In: KANT, Immanuel. Immanuel Kant: textos seletos. Tradução de Floriano de Sousa Fernandes. 2. ed. Petrópolis: Vozes, 1985. p. 100-117.

NOBRE, Marcos. Weber: racionalização e desencantamento do mundo. In: NOBRE, Marcos (org.). Curso livre de teoria crítica. Campinas: Papirus, 2018. E-book.

OLIVEIRA, Bernardo Jefferson de. Francis Bacon e a fundamentação da ciência como tecnologia. 2. ed. Belo Horizonte: Editora UFMG, 2010. 